\title{
PELAKSANAAN EKSTRAKURIKULER BOLA BASKET DI SMP NEGERI 18 KOTA BENGKULU
}

\author{
Deni Sujarwo \\ Penjas FKIP UNIB, email: deni.sujarwo1994@gmail.com
}

\author{
Arwin \\ Universitas bengkulu \\ Bayu Insanistyo \\ Universitas Bengkulu
}

\begin{abstract}
Abstrak
Tujuan dari penelitian ini yaitu untuk mengetahui gambaran bagaimana pelaksanaan ekstrakurikuler bola basket di SMP Negeri 18 Kota Bengkulu. Metode penelitian yang digunakan adalah metode penelitian yang berlandaskan pada filsafat postpositivesme,digunakan untuk meneliti pada kondisi obyek yang alamiah,(sebagai lawannya adalaha eksperimen) dimana peneliti adalah sesbagai instrument kunci,pengambilan sampel sumber data dilakukan secara purposive dan snowball. Subjek dalam penelitian ini adalah mahasiswa peneliti bidang studi penjaskes.dan Objek dalam penelitian ini adalah siswa-siswi SMP Negeri 18 kota Bengkulu,berjumlah sebanyak 35 siswa-siswi. Teknik analisis data yang digunakan dalam penelitian ini adalah tabulasi frekuensi dengan presentase. Hasil dari penelitian ini yang terdiri dari minat siswa sebagai atlet dapat dilihat dari gambaran persentase pengelolahan data yang rata-rata yang berminat 38,29\%, yang menyatakan Tidak rata-rata $61,71 \%$, guru penjas sebagai pelatih dapat dilihat dari gambaran persentase yaitu rata-rata menyatakan Ya $40 \%$,yang menyatakan Tidak $60 \%$.serta sarana dan prasarana yaitu rata-rata yang menyatakan Ya 20,86\%,yang menyatakan Tidak 79,14\%.Dengan demikian dapat disimpulkan bahwa minat siswa sebagai atlet bola basket di SMP Negeri 18 Kota bengkulu rendah,guru/pelatih bola basket di SMP Negeri 18 Kota Bengkulu kuurang baik dan sarana dan prasarana bola basket di SMP Negeri 18 Kota Bengkulu belum memenuhi standar internasional.
\end{abstract}

Kata Kunci :Ekstrakurikuler dan Bola Basket

\begin{abstract}
The purpose of this study is to know the description of how the implementation of basketball extracurricular in the country 18 cities bengkulu. Metode research used is a research method based on postpositivesme philosophy, used to examine the condition of natural objects, (as opposed to the experiment) Where researchers is as a key instrument, sampling of data source is done by purposive and snowball.Subjek in this research is student of research subject of Penjaskesrek and Object in this research is student of SMP Negeri 18 Kota Bengkulu, amounted
\end{abstract}


to 35 student. Which used in this research is tabulation of frequency with percentage. The result of this research is consist of interest of student as athlete can be seen from picture of percentage of data pengelolahan which the average of interest $38,29 \%$, which states not average $61,71 \%$ Teacher as coach can be seen $d$ Ari description percentage of the average that states Yes $40 \%$, which states No 60\%. And facilities and infrastructure is the average that states Yes $20.86 \%$, which states No $79.14 \%$. Thus it can be concluded that the interest of students As a basketball athlete in SMP Negeri 18 Kota Bengkulu low, teacher / basketball coach in SMP Negeri 18 Bengkulu City is not good and basketball facilities and infrastructure in SMP Negeri 18 Kota Bengkulu not meet International standards. So it can be concluded the implementation of extracurricular basketball in SMP Negeri 18 Kota Bengkulu not good.

\section{Keywords: Extracurricular and Basketball}

\section{PENDAHULUAN}

Berdasarkan pengamatan peneliti kegiatan ekstrakurikuler merupakan salah satu upaya pembinaan yang diselenggarakan di lingkungan sekolah dan dilaksanakan di luar jam pelajaran yang bertujuan untuk meningkatkan prestasi non akademik.

Dalam program ekstrakurikuler pendidikan jasmani/olahraga ada beberapa cabang yang diikuti siswa. Salah satu diantaranya adalah permainan bola basket. berjumlah 939 orang yang terdiri dari,lakilaki 429 dan perempuan 510.jadi,peminat ekstrakurikuler bola basket di SMP Negeri 18 Kota Bengkulu masih sangat kurang.

Sarana dan Prasarana,bola basket di SMP Negeri 18 Kota Bengkulu belum lengkap,karena belum memenuhi standar Internasional.line/garis lapangan yang kurang jelas,papan ring yang sudah lapuk,ring basket yang tidak ada lagi jarring.Bola basket yang tersedia cuma 4 bola. Ekstrakurikuler bola basket di SMP Negeri 18 Kota Bengkulu,Waktu latihan yang hanya 2 kali dalam seminggu tentu masih kurang sekali bagi siswa/atlet.

Rumusan masalah dalam penelitian yaitu :Bagaimanakah Pelaksanaan Ekstrakurikuler bola basket di SMP Negeri 18 Kota Bengkulu. Tujuan yang ingin di capai penelitian ini adalah : untuk mengetahui gambaran bagaimana pelaksanaan kegiatan ekstrakurikuler bola basket di SMP Negeri 18 Kota Bengkulu. Ekstrakurikuler adalah kegiatan yang dilakukan oleh para siswa sekolah atau Universitas di luar jam belajar kurikulum standar. Kegiatan-kegiatan ini ada pada setiap jenjang pendidikan dari sekolah dasar sampai universitas. (Saujana,2008). Permainan bola basket adalah olahraga berkelompok yang terdiri dari dua tim berlawanan dengan anggota masing-masing 5 orang, dimana tujuan permainan bola basket adalah memperoleh poin sebanyakbanyaknya dengan cara memasukkan bola ke dalam ring lawan. Pertandingan bola basket diselenggarakan di ruangan yang memiliki ukuran lapangan bola basket dengan panjang 28,5 meter dan lebar 15 meter. 
Teknik dasar permainan bola basket semakin berkembang dari awal penciptaannya yang hanya menggunakan teknik lemparan (John Oliver,2007). Berikut teknik dasar permainan bola basket yang yang perlu Anda ketahui:Dalam permainan bola basket, teknik menggiring bola disebut dengan dribble. Teknik yang satu ini bertujuan untuk membawa bola menghindari lawan atau mengumpannya pada kawan satu tim yang dekat dengan ring lawan. Perbedaan teknik menggiring dalam permainan bola basket dan sepak bola terletak pada cara pemain menggiring bolanya. Teknik mengumpan pada prinsipnya dilakukan untuk mengarahkan bola kepada rekan satu tim. Teknik ini dapat dilakukan dengan cara melempar bola kepada rekan satu tim setelah menggiring bola dengan satu atau dua tangan. bahu.

Teknik pivot digunakan untuk melakukan gerakan tipuan pada lawan. Caranya, pemain menggerakkan badan dengan bertumpu pada salah satu kaki dan kedua tangan menjaga bola dari serbuan lawan. Teknik shooting merupakan teknik dasar yang wajib dikuasai pemain untuk mendapatkan poin. Teknik ini dilakukan dengan cara memasukkan bola ke dalam ring lawan menggunakan teknik set shoot (diam di tempat dan memasukkan bola dengan satu atau dua tangan), jump shoot (memasukkan bola dengan melompat), dan lay up (memasukkan bola dengan berlari lalu melompat). Rebound ofensif merupakan lemparan yang gagal masuk kemudian dimasukkan lagi ke dalam ring oleh rekan tim dan jika berhasil masuk, tim mendapatkan dua poin. Sementara rebound defensif adalah teknik merebut bola yang gagal dimasukkan oleh lawan agar tidak ada lagi usaha untuk memasukkan bola ke ring. Pelatih dalam usaha meningkatkan prestasi atlet sangat penting karena dipundaknya terletak tugas dan tanggung jawab menmbawa atlet asuhannya kejenjang prestasi. Tugas lain dari seorang pelatih adalah sebagai pemimpin di dalam memimpin atlet asuhannya untuk memenuhi kebutuhankebutuhan atlet yang menyangkut,. menurut (Engkos Kosasih,1985:363).

\section{Siswa Sebagai Atlet}

Salah satu faktor yang paling penting dalam pencapaian prestasi pada permainan bola basket adalah faktor atlet. Karena atlet sebagai olahragawan adalah objek dari pekerjaan. Pelatih harus menciptakan faktor yang dapat mendorong olahragawan berusaha meningkatkan prestasinya yaitu dengan mengembangkan segala kualitasnya serta memahami olahragawan itu dengan segala aspek. Olahragawan yang baik mestinya memiliki serta mengembangankan secara sistematis kualitas seperti sehat,kondisi fisik baik,kesadaran tentang tugas, pengalaman bertanding dan kesadaran tentang tugas (Mulyadi,1998:16). Agar dapat menjadi suatu atlet yang berprestasi baik,tidak hanya terletak pada faktor usia saja, tetapi juga turut ditentukan oleh kondisi fisik. Hubungan antara kondisi fisik dan prestasi yang diperoleh dinyatakan sebagai hal yang saling menunjang. Kondisi fisik yang dimaksud dalam tulisan ini adalah faktor yang berkenan dengan bentuk tubuh dan kesegaran jasmani olahragawan.

\section{METODE}

Metode yang digunakan dalam penelitian ini adalah metode penelitian pendekatan kualitatif adalah metode 
penelitian yang berlandaskan pada filsafat postpositiveme, digunakan untuk meneliti pada kondisi obyek yang alamiah,(Sebagai lawannya adalah eksperimen) dimana peneliti adalah sebagai instrument kunci, pengambilan sampel sumber data dilakukan secara purposive dan snowball, teknik pengumpulan dengan trianggulasi (Gabungan), analisis data bersifat induktif/kualitatif dan hasil penelitian kualitatif lebih menekankan makna dari generalisasi. Menurut (Sugiyono,2015:15). Dalam mengikuti kegiatan ekstrakurikuler Bola Basket di SMP Negeri18 Kota Bengkulu.

Tempat dan waktu penelitian

Tempat penelitian ini dilakukan di SMP Negeri 18 Kota Bengkulu.

Waktu penelitian

Proses waktu penelitian ini dilakukan pada semester genap tahun ajaran 2016/2017,selama 1 bulan tanggal 15 juni15 juli 2017 ,pada hari Kamis dan Sabtu Pukul 15.00 s/d 17.30 WIB.

Subjek dan Objek Penelitian

Objek dalam penelitian ini adalah Ekstrakurikuler bola basket di SMP Negeri 18 Kota Bengkulu.

Teknik Pengumpulan Data

Dalam mengumpulkan data, penulis menggunakan beberapa metode yang lazim digunakan dalam berbagai penelitian ilmiah.

Observasi
Observasi adalah pengamatan dan pencatatan secara sistematik terhadap gejala yang tampak pada obyek penelitian. Metode ini penulis gunakan untuk memperoleh data tentang situasi dan kondisi umum SMP Negeri 18 Kota Bengkulu. Metode ini juga digunakan untuk mengetahui sarana dan prasarana yang ada, letak geografis serta untuk mengumpulkan data-data statistik lembaga pendidikan yang bersangkutan.

\section{Dokumentasi}

Metode dokumentasi adalah metode mencari data mengenai hal-hal atau variabel yang berupa catatan, transkrip, buku, surat kabar, majalah, prasasti, notulen,. Metode ini dipergunakan untuk memperoleh data tentang keadaan guru, jumlah siswa, sarana dan prasarana perpustakaan serta data-data lain yang bersifat dokumen. Metode ini dimaksudkan sebagai tambahan untuk bukti penguat.

Instrumen Penelitian

Untuk mendapatkan data dalam penelitian ini,peneliti menggunakan alat pengumpulan data berupa kuesioner. Berhubung belum adanya alat ukur yang baku dalam mengukur pelaksanaan kegiatan ekstrakurikuler Bola Basket, maka peneliti menyusun dan mengembangkan sendiri angket dan format yang akan digunakan, tetapi sebelumnya diberikan kepada pembimbing untuk dikoreksi terlebih dahulu.

Teknik Analisis Data

Proses analisis data dalam penelitian ini dilakukan dengan menggunakan analisi deskriftif yang menggunakan tabulasi 
frekuensi. Menurut (Arikunto, 1990:33), teknik analisis data ini dapat dirumuskan sebagai berikut :

$$
\mathrm{P}=\frac{f}{N} \times 100 \%
$$

Keterangan :

$\mathrm{P}$ : Persentase yang menjawab

$f \quad$ : frekuensi yang menjawab

$\mathrm{N}$ : jumlah seluruh responden

100\%:Bilangan tetap

\section{HASIL DAN PEMBAHASAN} Hasil

Dari hasil yang telah dilakukan dengan cara menyebarkan angket kepada responden yaitu siswa-siswi SMP Negeri 18 Kota Bengkulu berjumlah 35 orang dengan tiga variable penelitian hasilnya adalah sebagai berikut :

\section{Siswa Sebagai Atlet}

Variable siswa sebagai atlet dalam mengikuti ekstrakurikuler bola basket dari 35 orang responden,di peroleh pernyataan yang berminat olahraga bola basket yang berasal dari orang kaya 15 orang responden menyatakan Ya $(42,58 \%), 20$ orang responden menyatakan Tidak (57,15 \%). Pernyataan pemain bola basket hanya untuk orang yang berpostur tinggi 10 orang responden menyatakan $\mathrm{Ya}(28,57 \%), 25$ orang responden menyatakan Tidak $(71,43$ $\%)$.

Pernyataan olahraga bola basket memerlukan biaya yang mahal,9 orang responden menyatakan $\mathrm{Ya}(25,72$ \%),26 orang responden menyatakan Tidak (74,28\%). Pernyataan permainan bola basket hanya untuk orang kota,13 orang responden menyatakan $\mathrm{Ya}(37,15 \%), 22$ orang responden menyatakan Tidak $(62,85 \%)$. Pernyataan ada $50 \%$ siswa SMP Negeri 18 Kota Bengkulu yang mengikuti latihan bola basket,35 orang responden menyatakan Tidak (100 \%). Pernyataan bermain bola basket merupakan keinginan dari hati para siswa di SMP Negeri 18 Kota Bengkulu,18 orang responden menyatakan Ya $\quad(51,42 \quad \%), 17$ orang responden menyatakan Tidak (48,58 \%).

Pernyataan semua orang tua siswa menyuruh anaknya untuk bermain bola basket,15 orang responden menyatakan $\mathrm{Ya}$ $(42,85 \%), 20$ orang responden menyatakan Tidak (57,15 \%). Pernyataan olahraga bola basket banyak sekali manfaatnya terhadap pertumbuhan dan perkembangan seseorang,24 orang responden menyatakan $\mathrm{Ya} \quad(68,58 \%), 11$ orang responden menyatakan Tidak (31,42 \%). Pernyataan olahraga bola basket di minati oleh semua siswa,35 orang responden menyatakan Tidak (100\%). Pernyataan para atlet bola basket di SMP Negeri 18 Kota Bengkulu selalu hadir dalam latihan yang di jadwal,30 orang responden menyatakan $\mathrm{Ya}(85,71$ $\%), 5$ orang responden menyataakan Tidak $(14,29 \%)$.

\section{Pembahasan}

Berdasarkan dari analisa data yang telah diperoleh melalui angket diperoleh gambaran yang jelas mengenai pelaksanaan ekstrakurikuler bola basket di SMP Negeri 18 Kota Bengkulu sebagai berikut :

Siswa sebagai atlet

Dalam penelitian yang dilakukan oleh peneliti, terbukti minat siswa sebagai atlet dikategorikan rendah. (moelok, 1984:16). Tercapai atau tidaknya prestasi yang 
maksimal oleh atlet/pemain ditentukan oleh unsur-unsur yang dimiliki atlet tersebut sesuai dengan kebutuhan.

Dari analisa yang telah dilakukan pada penelitian ini minat siswa sebagai atlet rendah tidak memenuhi kriteria minimal, (Suharno, 1986:16).Kesimpulan dari pembahasan minat siswa sebagai atlet dapat dilihat dari gambaran persentase pengelolahan data yang rata-rata yang berminat $38,29 \%$, yang menyatakan Tidak rata-rata $61,71 \%$. Hal ini menggambarkan dengan jelas bahwa minat siswa SMP Negeri 18 Kota Bengkulu rendah. Disamping itu rendahnya minat siswa terhadap bola basket nampak pada jumlah siswa SMP Negeri 18 Kota Bengkulu adalah 939 yang mengikuti ekstrakurikuler bola basket hanya 35 siswa.

\section{Guru/ Pelatih}

Peran pelatih dalam usaha meningkatkan prestasi atlet sangat penting. Karena pelatih menentukan program latihan yang tepat bagi atlet dalam usaha meningkatkan prestasi. Selama penelitian yang dilaksanakan peneliti di SMP Negeri 18 Kota Bengkulu, terlihat bahwa peran guru Penjas sebagai pelatih kurang baik. Tugas dan peran guru penjas dalam meningkatkan prestasi atlet antara lain : sebagai bapak, sebagai pemimpin, sebagai pengawas dan menjalankan latihan, sebagai pemandu, sebagai perencana program, sebagai evaluator dan sekaligus sebagai peneliti (suharno, 1986:4). Hasil kerja seorang pelatih tergantung pada tingkat yang diberikan dan penyusunan program yang tepat bagi atlet asuhannya (Suharsono, 1986:5). pelaksanaan ekstrakurikuler bola basket di SMP Negeri 18 Kota Bengkulu kurang baik. Kesimpulan dari pembahasan guru penjas sebagai pelatih dapat dilihat dari gambaran persentase yaitu rata-rata menyatakan Ya 40 \%,yang menyatakan Tidak 60 \%.Maka dapat disimpulkan bahwa guru/pelatih bola basket di SMP Negeri 18 Kota bengkulu kurang baik.

Sarana dan prasarana

Proses kegiatan ekstrakurikuler akan dapat berjalan dengan lancar dan baik apabila tersedia sarana dan prasarana yang dibutuhkan. Bila sarana dan prasarana yang dibutuhkan tidak mencukupi maka akan menimbulkan berbagai masalah dan kendala di lapangan dalam mencapai tujuan. Kedudukan sarana dan prasarana adalah menunjang suatu proses belajar mengajar maupun latihan secara efektif dan efisien,(Sudijarto, 1987:27).

Dalam pelaksanaan ekstrakurikuler bola basket di SMP Negeri 18 Kota Bengkulu, masalah sarana dan prasarana belum sesuai dengan standar internasional. Kesimpulan dari pembahasan sarana dan prasarana dapat dilihat dari gambaran persentase menyatakan bahwa sarana dan prasarana yaitu rata-rata yang menyatakan Ya 20,86\%,yang menyatakan Tidak 79,14\%. Maka dapat disimpulkan bahwa sarana dan prasarana bola basket di SMP Negeri 18 Kota Bengkulu belum memenuhi standar internasional.

\section{PENUTUP}

Kesimpulan

Berdasarkan analisis data dan pembahasan yang telah dilakukan maka dapat ditarik suatu kesimpulan penelitian, 
yaitu : minat siswa sebagai atlet dapat dilihat dari gambaran persentase pengelolahan data yang rata-rata yang berminat $38,29 \%$, yang menyatakan Tidak rata-rata $61,71 \%$. Hal ini menggambarkan dengan jelas bahwa minat siswa SMP Negeri 18 Kota Bengkulu rendah. Disamping itu rendahnya minat siswa terhadap bola basket nampak pada jumlah siswa SMP Negeri 18 Kota Bengkulu adalah 939 yang mengikuti ekstrakurikuler bola basket hanya 35 siswa. Guru/ pelatih dapat dilihat dari gambaran persentase yaitu rata-rata menyatakan Ya $40 \%$,yang menyatakan Tidak 60 \%. Maka dapat disimpulkan bahwa guru/pelatih bola basket di SMP Negeri 18 Kota bengkulu kurang baik. Sarana dan prasarana dapat dilihat dari gambaran persentase menyatakan bahwa sarana dan prasarana yaitu rata-rata yang menyatakan Ya 20,86\%,yang menyatakan Tidak 79,14\%. Maka dapat disimpulkan bahwa sarana dan prasarana bola basket di SMP Negeri 18 Kota Bengkulu belum memenuhi standar internasional

\section{Saran}

\footnotetext{
Berdasarkan dari kesimpulan yang telah dikemukakan diatas maka dapat dikemukakan saran-saran sebagai berikut :

Diharapkan kepada siswa SMP Negeri 18 Kota Bengkulu yang mengikuti kegiatan ekstrakurikuler bola basket supaya minatnya lebih di tingkat .

Kepada guru pendidikan jasmani atau pelatih kegiatan ekstrakurikuler bola basket agar di tingkat lagi program latihan yang
}

telah ada pada siswa dan keahlian guru/pelatih supaya di tingkatkan,untuk lebih baik.

Kepada kepala sekolah SMP Negeri 18 Kota Bengkulu diharapkan untuk lebih meningkatkan lagi sarana dan prasarana permainan bola basket sehingga memenuhi standar Internasional, pelaksanaan kegiatan ekstrakurikuler dapat berjalan dengan lancar dan peserta kegiatan dapat untuk meningkatkan prestasi.

\section{DAFTAR PUSTAKA}

Atika, Sabillah.(2012), Pengertian Subjek Penelitian. Dimuat dalam http://sabillahatika.blogspot.com/2012/ 12/bab-8-subjek-penelitian.html.

Kosasih Engkos. (1985), Olahraga Teknikdan Program Latihan.Akademi Presindo. Jakarta

Mulyadi. (1998), PembinaanPrestasi Bola Basket di Unit Kegiatan Bolas Basket. IKIP Padang. FPOK. Padang.

Saputra, Aditya. (2014), StudiKasusTentangPelaksanaanKegiatan Ekstrakulikuler Bola Basket di SMA Negeri 01 PondokKelapaKabupaten Bengkulu Tengah.Skripsi. Universitas Bengkulu.

Sugiyono.(2015).MetodePenelitianPendidik anKuantitatifdankualitatif. FPOK IKIP Padang. 